\title{
Asclepiadaceae endémicas del Perú
}

Blanca León ${ }^{1,2}$

${ }^{1}$ Museo de Historia Natural, Av. Arenales 1256, Aptdo. 14-0434, Lima 14, Perú

2 Plant Resources Center, University of Texas at Austin, Austin TX 78712 EE.UU.

blanca.leon@mail.utexas.edu

\section{Resumen}

La familia Asclepiadaceae es reconocida en el Perú por presentar 27 géneros y 107 especies (Brako \& Zarucchi, 1993), mayormente bejucos y hierbas. Esta familia se halla bajo revisión sistemática. Para la flora peruana, estos estudios en desarrollo probablemente concluyan con la necesidad de un reordenamiento de los taxones a nivel de los géneros (S. Liede, com. pers.). Dada la escasez de colecciones herborizadas y la falta de consenso sobre los taxones, aquí se reconocen provisionalmente 43 endemismos. En general, los endemismos en esta familia ocupan las regiones Mesoandina y Bosques Muy Húmedos Montanos, entre los 900 y 2600 m de altitud. Se aplicaron las categorías y criterios de la UICN a cinco especies. Dos endémicas se encuentran registradas en el Sistema Nacional de Áreas Naturales Protegidas por el Estado.

Palabras claves: Asclepiadaceae, Perú, endemismo, plantas endémicas.

\section{Abstract}

The Asclepiadaceae are represented in Peru by 27 genera and 107species (Brako \& Zarucchi, 1993), mostly vines and lianas. The family is under systematic revision, and these ongoing studies are likely to result in genus-level changes for the Peruvian Asclepiadaceae flora (S. Liede, pers. comm.). Given the scarcity of collections and the lack of consensus on the taxonomic status of several taxa, we provisionally recognize 43 endemic species. The endemic taxa are found in the Mesoandean and Very Humid Montane Forest regions, between 900 and 2600 m elevation. We applied IUCN categories and criteria to five species. Two endemic species have been found in protected areas.

Keywords: Asclepiadaceae, Peru, endemism, endemic plants.

\section{Astephanus peruvianus E. Fourn.}

Publicación: Ann. Sci. Nat., Bot., ser. 6, 14: 367. 1882.

Colección tipo: H. Ruiz \& J. Pavón s.n.

Herbarios: B, LE.

Nombre común: Desconocido.

Registro departamental: Sin datos.

Regiones Ecológicas: Sin datos; altitud desconocida.

SINANPE: Sin registro.

Herbarios peruanos: Ninguno.

Observaciones: Este taxón fue considerado por Brako \& Zarucchi (1993) como un endemismo; sin embargo, no ha sido posible evaluarlo, ni asignarle una categoría.

\section{Cynanchum calycinum (Schltr.) Morillo}

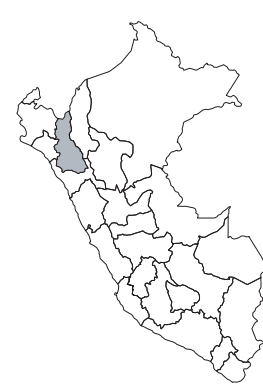

Publicación: Ernstia n.s. 2(3-4): 68. 1992.

Colección tipo: A. Weberbauer 6227

Herbarios: G.

Nombre común: Desconocido.

Registro departamental: CA.

Regiones Ecológicas: BS; 400—500 m.

SINANPE: Sin registro.

Herbarios peruanos: Ninguno.

Observaciones: Este taxón fue considerado por Brako \& Zarucchi (1993) como un endemismo; sin embargo, no ha sido posible evaluarlo, ni asignarle una categoría.

\section{Cynanchum canoi Morillo}

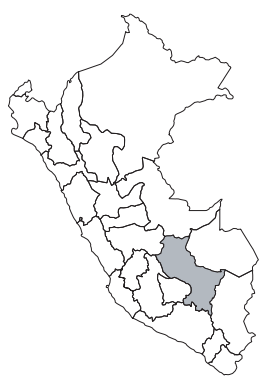

Publicación: Ernstia n.s. 4(1-2): 4. 1994.

Colección tipo: A. Cano 5365

Herbarios: MERF; USM.

Nombre común: Desconocido.

Registro departamental: CU.

Regiones Ecológicas: BMHM; 3350$3400 \mathrm{~m}$.

SINANPE: PNM

Herbarios peruanos: USM (holotipo citado).

Observaciones: Este taxón fue descrito posterior a Brako \& Zarucchi (1993); no ha sido posible evaluarlo, ni asignarle una categoría.

\section{Cynanchum hickenii Malme}

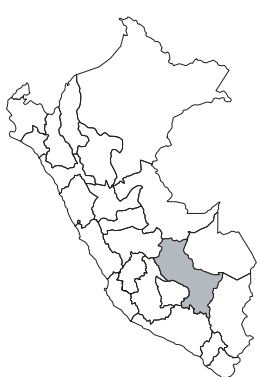

Publicación: Ark. Bot. 25A(7): 5. 1932.

Colección tipo: Hicken 71

Herbarios:

Nombre común: Desconocido.

Registro departamental: CU.

Regiones Ecológicas: PSH; 3500 m.

SINANPE: Sin registro.

Herbarios peruanos: Ninguno.

Observaciones: Este taxón fue considerado por Brako \& Zarucchi (1993) como un endemismo; sin embargo, no ha sido posible evaluarlo, ni asignarle una categoría. 


\section{Cynanchum luteynii Morillo}

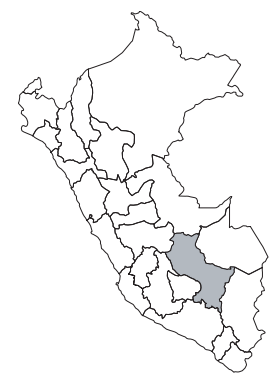

Publicación: Ernstia n.s. 2(3-4): 64. 1992.

Colección tipo: J. Luteyn \& M. LebrónLuteyn 6436

Herbarios: AAU, NY.

Nombre común: Desconocido,

Registro departamental: CU.

Regiones Ecológicas: BMHM; $3170 \mathrm{~m}$.

SINANPE: Sin registro.

Herbarios peruanos: Ninguno.

Observaciones: Esta especie se conoce del ejemplar tipo recolectado cerca al Parque Nacional Manu, dentro de la Reserva de la Biosfera. No ha sido posible evaluarla, ni asignarle una categoría.

\section{Cynanchum peruvianum (Schltr.) Morillo}

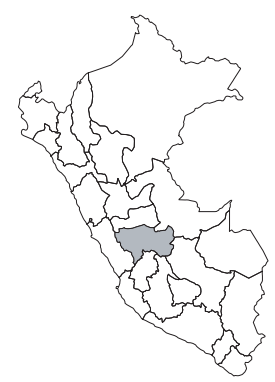

Publicación: Ernstia n.s. 2(3-4): 69. 1992.

Colección tipo: A. Weberbauer 2041

Herbarios: G; MOL!

Nombre común: Desconocido.

Registro departamental: JU.

Regiones Ecológicas: BMHM; 2000$2100 \mathrm{~m}$.

SINANPE: Sin registro.

Herbarios peruanos: MOL (isotipo).

Observaciones: Este taxón fue considerado por Brako \& Zarucchi (1993) como un endemismo; sin embargo, no ha sido posible evaluarlo, ni asignarle una categoría.

\section{Cynanchum thymifolium (Schltr.) Morillo}

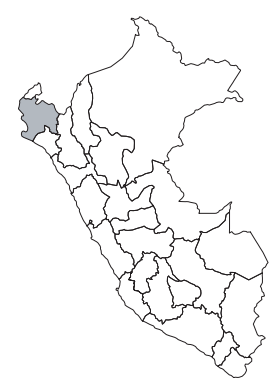

Publicación: Ernstia n.s. 2(3-4): 69. 1992.

Colección tipo: A. Weberbauer 6277

Herbarios: US.

Nombre común: Desconocido.

Registro departamental: PI.

Regiones Ecológicas: MDE; 1700 -1800 m. SINANPE: Sin registro.

Herbarios peruanos: Ninguno.

Observaciones: Este taxón fue considerado por Brako \& Zarucchi (1993) como un endemismo; sin embargo, no ha sido posible evaluarlo, ni asignarle una categoría.

\section{Cynanchum tiaratum Malme}

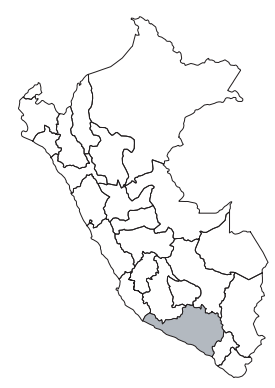

Publicación: Ark. Bot. 25A(7): 7, f. 5. 1932.

Colección tipo: A. Weberbauer 6875

Herbarios: F; MOL!

Nombre común: Desconocido.

Registro departamental: AR.

Regiones Ecológicas: MA; $2800 \mathrm{~m}$.

SINANPE: Sin registro.

Herbarios peruanos: MOL (isotipo).

Observaciones: Este taxón fue considerado por Brako \& Zarucchi (1993) como un endemismo; sin embargo, no ha sido posible evaluarlo, ni asignarle una categoría.

\section{Cynanchum unguiculatum Markgr.}

Publicación: Notizbl. Bot. Gart. BerlinDahlem 11(108): 788-789. 1933.

Colección tipo: H. Ruiz \& J. Pavón 5/80 Herbarios: MA.

Nombre común: Desconocido. Registro departamental: Sin datos.

Regiones Ecológicas: Sin datos; altitud desconocida.

SINANPE: Sin registro.

Herbarios peruanos: Ninguno.

Observaciones: Este taxón fue considerado por Brako \& Zarucchi (1993) como un endemismo; sin embargo, no ha sido posible evaluarlo, ni asignarle una categoría.

\section{Ditassa crassa Schltr.}

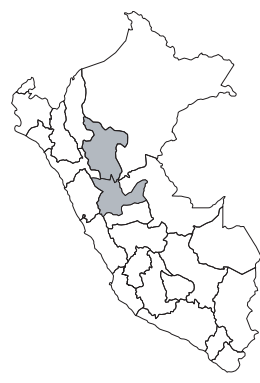

Publicación: Bot. Jahrb. Syst. 37: 611612. 1906.

Colección tipo: A. Weberbauer 3486

Herbarios: B; MOL!

Nombre común: Desconocido.

Registro departamental: HU, SM.

Regiones Ecológicas: BMHM; 1200$1300 \mathrm{~m}$.

SINANPE: Sin registro.

Herbarios peruanos: MOL (isotipo).

Observaciones: Este taxón fue considerado por Brako \& Zarucchi (1993) como un endemismo; sin embargo, no ha sido posible evaluarlo, ni asignarle una categoría.

\section{Ditassa gracilipes Schltr.}

\section{EN, B1ab(iii)}

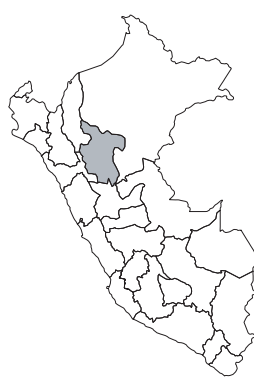

Publicación: Bot. Jahrb. Syst. 37: 612613. 1906.

Colección tipo: A. Weberbauer 4543

Herbarios: B; MOL!.

Nombre común: Desconocido.

Registro departamental: SM.

Regiones Ecológicas: BMHP; 900—1100 $\mathrm{m}$.

SINANPE: Sin registro.

Herbarios peruanos: HAO (1), MOL (isotipo).

Observaciones: Bejuco conocido aparentemente de dos colecciones realizadas en la cuenca del Mayo. El ejemplar tipo fue recolectado en 1904. Amenazas a sus poblaciones están asociadas a deforestación.

\section{Ditassa peruviana Morillo}

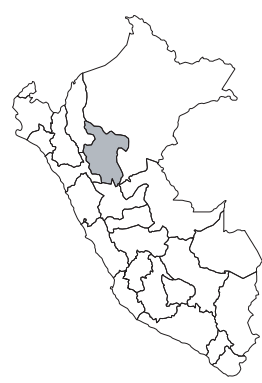

Publicación: Ernstia 51: 11. 1989.

Colección tipo: G. Klug 3405

Herbarios: GH, NY.

Nombre común: Desconocido.

Registro departamental: SM.

Regiones Ecológicas: BMHP; $1200-$ $1600 \mathrm{~m}$.

SINANPE: Sin registro.

Herbarios peruanos: Ninguno. 
Observaciones: Este taxón fue considerado por Brako \& Zarucchi (1993) como un endemismo; sin embargo, no ha sido posible evaluarlo, ni asignarle una categoría.

\section{Ditassa violascens Schltr.}

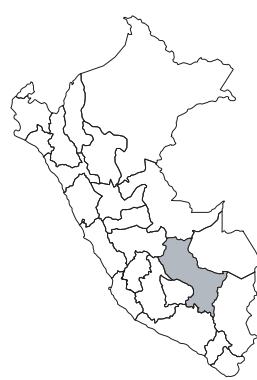

Publicación: Bot. Jahrb. Syst. 37: 613. 1906.

Colección tipo: A. Weberbauer 5007

Herbarios: B.

Nombre común: Desconocido.

Registro departamental: CU.

Regiones Ecológicas: BMHM; 2100$2300 \mathrm{~m}$.

SINANPE: Sin registro.

Herbarios peruanos: Ninguno.

Observaciones: Este taxón fue considerado por Brako \& Zarucchi (1993) como un endemismo; sin embargo, no ha sido posible evaluarlo, ni asignarle una categoría.

\section{Ditassa weberbaueri Schltr.}

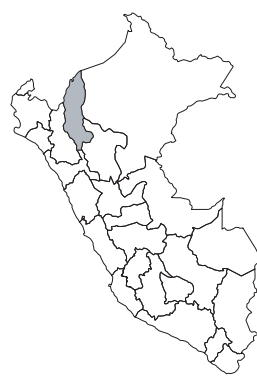

Publicación: Bot. Jahrb. Syst. 37: 613. 1906.

Colección tipo: A. Weberbauer 4276

Herbarios: B; MOL!.

Nombre común: Desconocido.

Registro departamental: AM.

Regiones Ecológicas: BMHM; 2000-

$2100 \mathrm{~m}$.

SINANPE: Sin registro.

Herbarios peruanos: MOL (isotipo).

Observaciones: Este taxón fue considerado por Brako \& Zarucchi (1993) como un endemismo; sin embargo, no ha sido posible evaluarlo, ni asignarle una categoría.

\section{Gonolobus marginatus Schltr.}

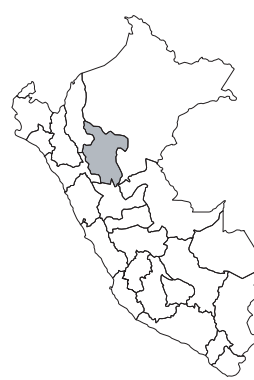

Publicación: Bot. Jahrb. Syst. 37: 626627.1906.

Colección tipo: A. Weberbauer 4635

Herbarios: B.

Nombre común: Desconocido.

Registro departamental: SM.

Regiones Ecológicas: BMHP; $800-900 \mathrm{~m}$.

SINANPE: Sin registro.

Herbarios peruanos: Ninguno.

Observaciones: Este taxón fue considerado por Brako \& Zarucchi (1993) como un endemismo; sin embargo, no ha sido posible evaluarlo, ni asignarle una categoría.

\section{Gonolobus peruanus Schltr.}

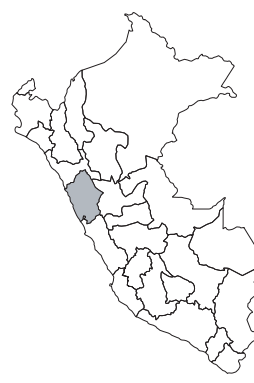

Publicación: Bot. Jahrb. Syst. 37: 627. 1906.

Colección tipo: A. Weberbauer 3191

Herbarios: B.

Nombre común: Desconocido.

Registro departamental: AN.

Regiones Ecológicas: MA; $2200 \mathrm{~m}$.

SINANPE: Sin registro.

Herbarios peruanos: Ninguno.
Observaciones: Este taxón fue considerado por Brako \& Zarucchi (1993) como un endemismo; sin embargo, no ha sido posible evaluarlo, ni asignarle una categoría.

\section{Gonolobus purpureus Morillo}

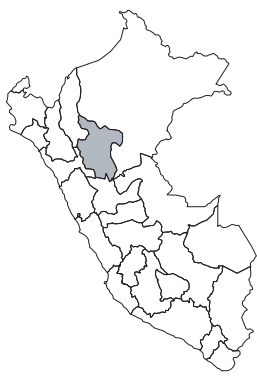

Publicación: Anales Jard. Bot. Madrid 47(2): 354. [1990]. 1989

Colección tipo: J. Schunke V. 7656

Herbarios: MO.

Nombre común: Desconocido.

Registro departamental: SM.

Regiones Ecológicas: BMHP; $500-850 \mathrm{~m}$. SINANPE: Sin registro.

Herbarios peruanos: Ninguno.

Observaciones: Este taxón fue considerado por Brako \& Zarucchi (1993) como un endemismo; sin embargo, no ha sido posible evaluarlo, ni asignarle una categoría.

\section{Gonolobus sagasteguii Morillo}

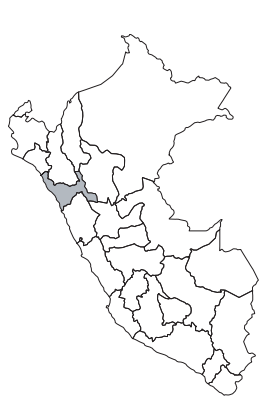

$$
\text { CR, B1a }
$$

Publicación: Ernstia 50: 17, 19. 1988. Colección tipo: A. Sagástegui A. et al. 9413

Herbarios: NY

Nombre común: Desconocido. Registro departamental: LL.

Regiones Ecológicas: MA; 2100—2600 m. SINANPE: Sin registro.

Herbarios peruanos: Ninguno.

Observaciones: Bejuco conocido solamente de una localidad en la vertiente del Pacífico, en la cuenca del Chicama. Esta especie fue citada como procedente de Cajamarca (Brako \& Zarucchi, 1993), pero Lledén hoy está reconocido en La Libertad.

\section{Marsdenia oligantha K. Schum.}

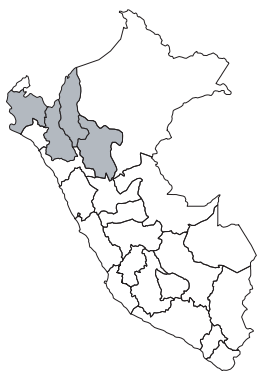

Publicación: Verh. Bot. Vereins Prov. Brandenburg 47: 189. 1905.

Colección tipo: E.H.G. Ule 6603

Herbarios: HBG.

Nombre común: Desconocido.

Registro departamental: AM, CA, SM.

Regiones Ecológicas: BMHP, BHA; 500-750 m.

SINANPE: Sin registro.

Herbarios peruanos: Ninguno.

Observaciones: Este taxón fue considerado por Brako \& Zarucchi (1993) como un endemismo; sin embargo, no ha sido posible evaluarlo, ni asignarle una categoría.

\section{Marsdenia weberbaueri Schltr. \& Rothe}

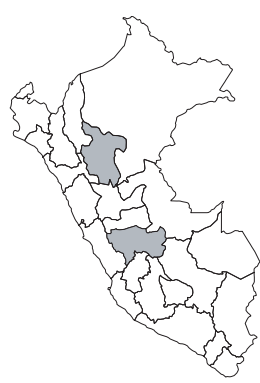

Publicación: Bot. Jahrb. Syst. 53: 431. 1915.

Colección tipo: A. Weberbauer 1911

Herbarios: MOL!

Nombre común: Desconocido.

Registro departamental: JU, SM.

Regiones Ecológicas: BMHP; $1000 \mathrm{~m}$.

SINANPE: Sin registro.

Herbarios peruanos: MOL (isotipo). 
Observaciones: Este taxón fue considerado por Brako \& Zarucchi (1993) como un endemismo; sin embargo, no ha sido posible evaluarlo, ni asignarle una categoría.

\section{Matelea aliciae Morillo}

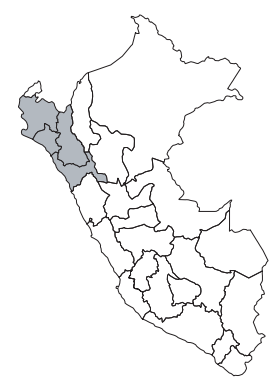

Publicación: Anales Jard. Bot. Madrid 43: 238-239. [1987] 1986.

Colección tipo: A. Lourteig \& A. López M. 2996

Herbarios: P, VEN.

Nombre común: Desconocido,

Registro departamental: CA, LL, LA, PI. Regiones Ecológicas: DST, MDE; 210$950 \mathrm{~m}$.

SINANPE: Sin registro.

Herbarios peruanos: CPUN (4), HAO (3).

Observaciones: Este taxón fue considerado por Brako \& Zarucchi (1993) como un endemismo; sin embargo, no ha sido posible evaluarlo, ni asignarle una categoría.

\section{Matelea camiloana Morillo}

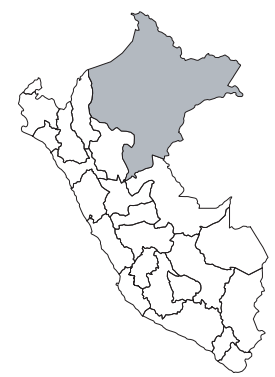

Publicación: Ernstia 50: 20. 1988.

Colección tipo: L. Williams 4392

Herbarios: F.

Nombre común: Desconocido.

Registro departamental: LO.

Regiones Ecológicas: BHA; altitud desconocida.

SINANPE: Sin registro.

Herbarios peruanos: Ninguno.

Observaciones: Este taxón fue considerado por Brako \& Zarucchi (1993) como un endemismo; sin embargo, no ha sido posible evaluarlo, ni asignarle una categoría.

\section{Matelea glandulosa (Poepp. ex Decne) Morillo}

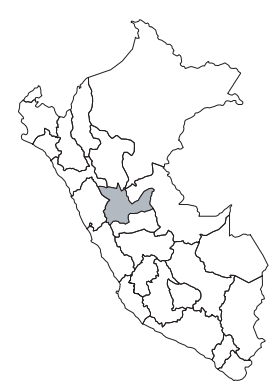

Publicación: Ernstia 24: 35. 1984. Colección tipo: E.F. Poeppig 1418

Herbarios: P, W.

Nombre común: Desconocido,

Registro departamental: HU.

Regiones Ecológicas: BHA; altitud desconocida.

SINANPE: Sin registro.

Herbarios peruanos: Ninguno.

Observaciones: Este taxón fue considerado por Brako \& Zarucchi (1993) como un endemismo; sin embargo, no ha sido posible evaluarlo, ni asignarle una categoría.

\section{Matelea klugii Morillo}

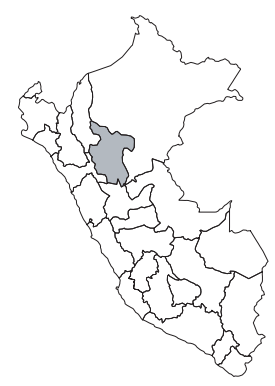

Publicación: Anales Jard. Bot. Madrid 47(2): 356. [1990] 1989.

Colección tipo: G. Klug 4342

Herbarios: BM, F, K, MO, S, US; USM!.

Nombre común: Desconocido.

Registro departamental: SM.

Regiones Ecológicas: BHA; altitud desconocida.

SINANPE: Sin registro.

Herbarios peruanos: USM (isotipo).
Observaciones: Este taxón fue considerado por Brako \& Zarucchi (1993) como un endemismo; sin embargo, no ha sido posible evaluarlo, ni asignarle una categoría.

\section{Matelea longifolia (Markgr.) Morillo}

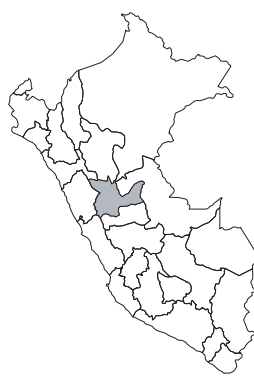

Publicación: Ernstia 24: 36. 1984.

Colección tipo: H. Ruiz \& J. Pavón 5/75

Herbarios: MA.

Nombre común: Desconocido.

Registro departamental: HU.

Regiones Ecológicas: BHA; altitud desconocida.

SINANPE: Sin registro.

Herbarios peruanos: Ninguno.

Observaciones: Este taxón fue considerado por Brako \& Zarucchi (1993) como un endemismo; sin embargo, no ha sido posible evaluarlo, ni asignarle una categoría.

\section{Matelea marginata Morillo}

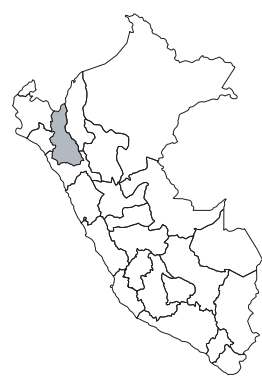

Publicación: Ernstia 29: 6. 1985.

Colección tipo: P.C. Hutchison \& K. von Bismarck 6332

Herbarios: F, K, M, MICH, MO, NY, US; USM.

Nombre común: Desconocido.

Registro departamental: CA.

Regiones Ecológicas: MA; $1900 \mathrm{~m}$.

SINANPE: Sin registro.

Herbarios peruanos: USM (isotipo citado).

Observaciones: Este taxón fue considerado por Brako \& Zarucchi (1993) como un endemismo; sin embargo, no ha sido posible evaluarlo, ni asignarle una categoría.

\section{Matelea melinii (Malme) Morillo}

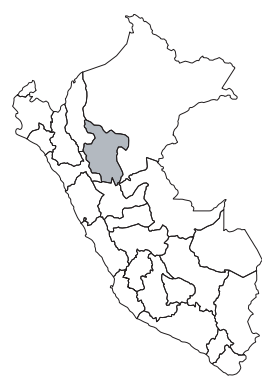

Publicación: Anales Jard. Bot. Madrid 43: 244. [1987] 1986.

Colección tipo: D. Melin 80

Herbarios: S.

Nombre común: Desconocido.

Registro departamental: SM.

Regiones Ecológicas: BHA; altitud desconocida.

SINANPE: Sin registro.

Herbarios peruanos: Ninguno.

Observaciones: Este taxón fue considerado por Brako \& Zarucchi (1993) como un endemismo; sin embargo, no ha sido posible evaluarlo, ni asignarle una categoría.

\section{Matelea pedicellata (Malme) Morillo}

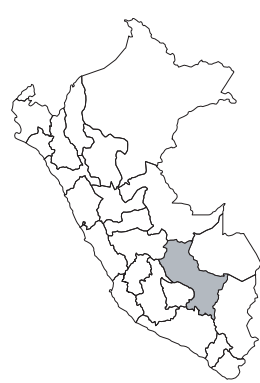

Publicación: Ernstia 18: 10. 1983.

Colección tipo: A. Weberbauer 6959

Herbarios: F, MO, US; USM!.

Nombre común: Desconocido.

Registro departamental: CU.

Regiones Ecológicas: BMHP; $700 \_800 \mathrm{~m}$.

SINANPE: Sin registro.

Herbarios peruanos: USM (isotipo). 
Observaciones: Este taxón fue considerado por Brako \& Zarucchi (1993) como un endemismo; sin embargo, no ha sido posible evaluarlo, ni asignarle una categoría.

\section{Matelea peruviana Morillo}

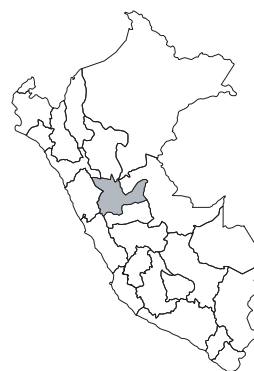

Publicación: Mem. Soc. Ci. Nat. La Salle 40: 76. 1980.

Colección tipo: J. Schunke V. 1356

Herbarios: MO.

Nombre común: Desconocido.

Registro departamental: HU.

Regiones Ecológicas: BHA; 300—400 m.

SINANPE: Sin registro.

Herbarios peruanos: Ninguno.

Observaciones: Este taxón fue considerado por Brako \& Zarucchi (1993) como un endemismo; sin embargo, no ha sido posible evaluarlo, ni asignarle una categoría.

\section{Matelea ruiz-pavonii Morillo}

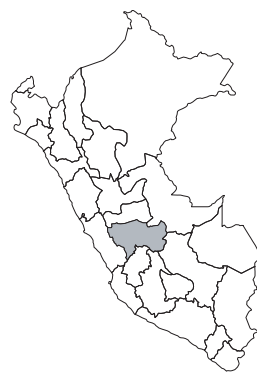

Publicación: Anales Jard. Bot. Madrid 47(2): 357-358. [1990] 1989.

Colección tipo: H. Ruiz \& J. Pavón 5/94

Herbarios: BM, MA.

Nombre común: Desconocido.

Registro departamental: JU.

Regiones Ecológicas: BMHP; altitud desconocida.

SINANPE: Sin registro,

Herbarios peruanos: Ninguno.

Observaciones: Este taxón fue considerado por Brako \& Zarucchi (1993) como un endemismo; sin embargo, no ha sido posible evaluarlo, ni asignarle una categoría.

\section{Matelea schunkei Morillo}

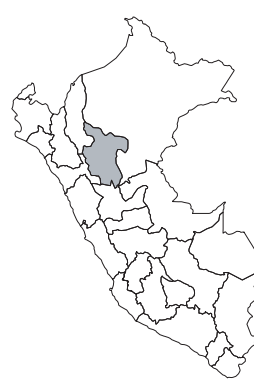

Publicación: Anales Jard. Bot. Madrid 47(2): 358. [1990]. 1989.

Colección tipo: J. Schunke V. 3206

Herbarios: F, COL.

Nombre común: Desconocido.

Registro departamental: SM.

Regiones Ecológicas: BHA; $500 \mathrm{~m}$

SINANPE: Sin registro.

Herbarios peruanos: Ninguno.

Observaciones: Este taxón fue considerado por Brako \& Zarucchi (1993) como un endemismo; sin embargo, no ha sido posible evaluarlo, ni asignarle una categoría.

\section{Matelea subsessilifolia Morillo}

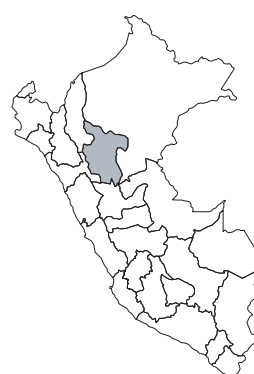

Publicación: Ernstia 29: 8. 1985.

Colección tipo: J. Schunke V. 9830

Herbarios: U.

Nombre común: Desconocido.

Registro departamental: SM.

Regiones Ecológicas: BHA; 300—500 m.

SINANPE: Sin registro.

Herbarios peruanos: Ninguno.
Observaciones: Este taxón fue considerado por Brako \& Zarucchi (1993) como un endemismo; sin embargo, no ha sido posible evaluarlo, ni asignarle una categoría.

\section{Matelea vargasii Morillo}

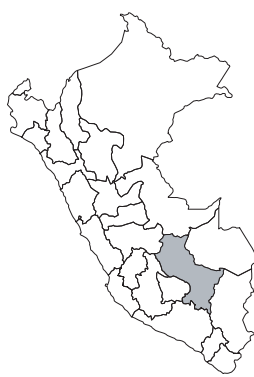

Publicación: Ernstia 50: 28-29. 1988.

Colección tipo: C. Vargas C. 4182

Herbarios: $\mathrm{GH}$

Nombre común: Desconocido.

Registro departamental: CU.

Regiones Ecológicas: BMHM; $1800 \mathrm{~m}$.

SINANPE: Sin registro.

Herbarios peruanos: Ninguno.

Observaciones: Este taxón fue considerado por Brako \& Zarucchi (1993) como un endemismo; sin embargo, no ha sido posible evaluarlo, ni asignarle una categoría.

\section{Matelea weberbaueri Morillo}

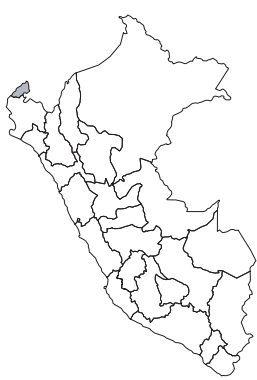

Publicación: Anales Jard. Bot. Madrid 42(2): 359. [1990] 1989.

Colección tipo: A. Weberbauer 7635

Herbarios:

Nombre común: Desconocido.

Registro departamental: TU.

Regiones Ecológicas: MDE; 800—900 m.

SINANPE: Sin registro.

Herbarios peruanos: Ninguno.

Observaciones: Este taxón fue considerado por Brako \& Zarucchi (1993) como un endemismo; sin embargo, no ha sido posible evaluarlo, ni asignarle una categoría.

\section{Matelea woytkowskii Morillo}

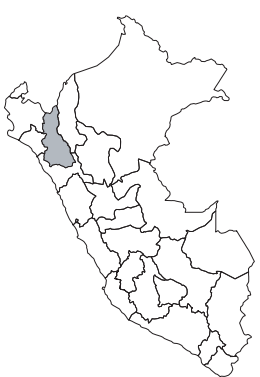

\section{NE}

Publicación: Ernstia 50: 29. 1988.

Colección tipo: F. Woytkowski 5694

Herbarios: GH.

Nombre común: Desconocido.

Registro departamental: CA.

Regiones Ecológicas: MA; $1200 \mathrm{~m}$.

SINANPE: Sin registro.

Herbarios peruanos: Ninguno.

Observaciones: Bejuco conocido solamente de la colección tipo.

\section{Metastelma rariflorum Schltr.}

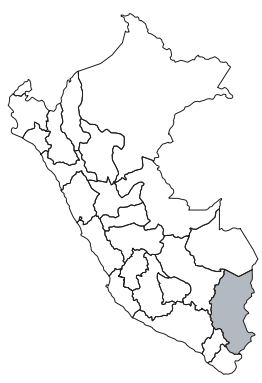

Publicación: Bot. Jahrb. Syst. 37: 610. 1906.

Colección tipo: A. Weberbauer 845

Herbarios: B; MOL!

Nombre común: Desconocido.

Registro departamental: PU.

Regiones Ecológicas: BMHM; 2100$2200 \mathrm{~m}$.

SINANPE: Sin registro.

Herbarios peruanos: MOL (isotipo).

Observaciones: Este taxón fue considerado por Brako \& Zarucchi (1993) como un endemismo; sin embargo, no ha sido posible evaluarlo, ni asignarle una categoría. 


\section{Orthosia tarmensis Schltr.}

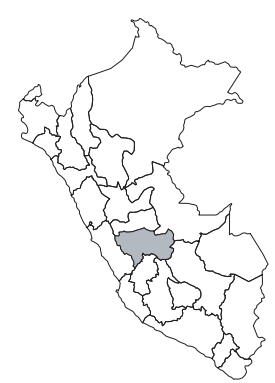

Publicación: Bot. Jahrb. Syst. 37: 619620. 1906.

Colección tipo: A. Weberbauer 2360

Herbarios: B.

Nombre común: Desconocido.

Registro departamental: JU.

Regiones Ecológicas: MA; 3000—3300 m.

SINANPE: Sin registro.

Herbarios peruanos: Ninguno.

Observaciones: Este taxón fue considerado por Brako \& Zarucchi (1993) como un endemismo; sin embargo, no ha sido posible evaluarlo, ni asignarle una categoría.

\section{Oxypetalum albiflorum Decne.}

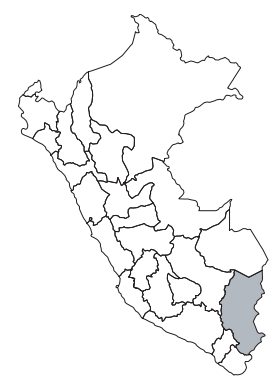

Publicación: Prodr. 8: 587. 1844.

Colección tipo: A. d’Orbigny 1065

Herbarios: P.

Nombre común: Desconocido.

Registro departamental: PU.

Regiones Ecológicas: PSH; altitud desconocida.

SINANPE: Sin registro.

Herbarios peruanos: Ninguno.

Observaciones: Este taxón fue considerado por Brako \& Zarucchi (1993) como un endemismo; sin embargo, no ha sido posible evaluarlo, ni asignarle una categoría.

\section{Oxypetalum weberbaueri Schltr.}

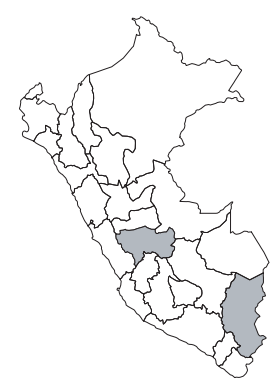

Publicación: Bot. Jahrb. Syst. 37: 622623. 1906.

Colección tipo: A. Weberbauer 666; A. Weberbauer 2009

Herbarios: B; MOL (sintipo 2009)!.

Nombre común: Desconocido.

Registro departamental: JU, PU.

Regiones Ecológicas: BMHM; 1900$2100 \mathrm{~m}$.

SINANPE: Sin registro.

Herbarios peruanos: MOL (sintipo Weberbauer 2009).

Observaciones: Este taxón fue considerado por Brako \& Zarucchi (1993) como un endemismo; sin embargo, no ha sido posible evaluarlo, ni asignarle una categoría.

\section{Philibertia peruviana (Schltr.) Goyder}

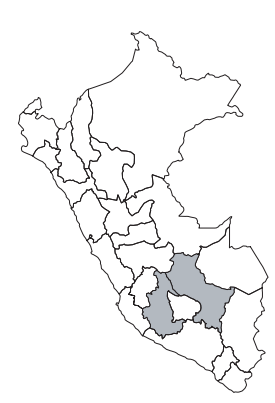

\section{DD}

Publicación: Kew Bull. 59(3): 437. 2004.

Colección tipo: A. Weberbauer 5514

Herbarios: B(d).

Nombre común: Desconocido.

Registro departamental: AY, CU.

Regiones Ecológicas: MA; 3000—3200

m.

SINANPE: Sin registro.

Herbarios peruanos: Ninguno.
Observaciones: Este bejuco es conocido de dos poblaciones en el sur del país; fue descrito de una planta recolectada en 1910 de los alrededores de Ayacucho. Dado que este tipo de plantas es escasamente recolectado se cuenta con escasa información sobre la situación de sus poblaciones.

\section{Schistonema weberbaueri Schltr.}

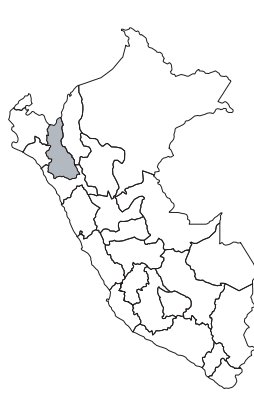

\section{DD}

Publicación: Bot. Jahrb. Syst. 37: 604605. 1906.

Colección tipo: A. Weberbauer 4145

Herbarios: B; MOL!

Nombre común: Desconocido.

Registro departamental: CA.

Regiones Ecológicas: MDE; 1300—2000 $\mathrm{m}$.

SINANPE: Sin registro.

Herbarios peruanos: MOL (isotipo).

Observaciones: Bejuco conocido aparentemente sólo de la colección tipo, una planta recolectada en 1904 de la vertiente occidental del sur de Cajamarca, en la cuenca del Chancay. Esta especie es la única representante de este género endémico al país.

\section{Stenomeria fosteri Morillo}

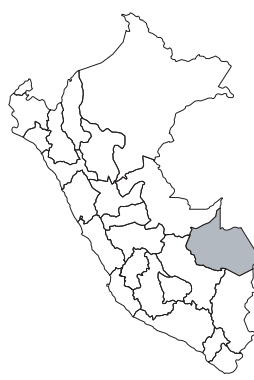

Publicación: Acta Bot. Venez. 16(1): 8587, f. 1. 1990.

Colección tipo: R.B. Foster 2705

Herbarios: F.

Nombre común: Desconocido.

Registro departamental: MD.

Regiones Ecológicas: BHA; altitud desconocida.

SINANPE: PNM

Herbarios peruanos: Ninguno.

Observaciones: Este taxón fue considerado por Brako \& Zarucchi (1993) como un endemismo; sin embargo, no ha sido posible evaluarlo, ni asignarle una categoría.

\section{Tassadia cordata Malme}

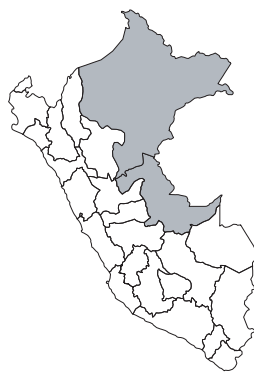

Publicación: Ark. Bot. 29A(13): 4. 1939. Colección tipo: G. Tessmann 3380

Herbarios: G.

Nombre común: Desconocido.

Registro departamental: LO, UC.

Regiones Ecológicas: BHA; altitud desconocida.

SINANPE: Sin registro.

Herbarios peruanos: Ninguno.

Observaciones: Este taxón fue considerado por Brako \& Zarucchi (1993) como un endemismo; sin embargo, no ha sido posible evaluarlo, ni asignarle una categoría. 